\title{
Ribonucleotide reductase subunit M2 as a novel target for clear-cell renal cell carcinoma
}

This article was published in the following Dove Press journal:

OncoTargets and Therapy

\section{Yun Zou \\ Juan Zhou \\ Bin Xu \\ Wenzhi Li \\ Zhong Wang}

Department of Urology and Andrology, Shanghai Ninth People's Hospital,

Shanghai Jiao Tong University School of Medicine, Shanghai 2000II, People's

Republic of China
Correspondence: Zhong Wang; Wenzhi Li Department of Urology and Andrology, Shanghai Ninth People's Hospital, Shanghai jiao Tong University School of Medicine, No. 639 Zhizaoju Road, Shanghai 2000II, People's Republic of China

Email zhongwang2000@sina.com; wenjhylee@hotmail.com
Background: Sufficient supply of deoxyribonucleoside triphosphates (dNTPs) is required for the uncontrolled replication of cancers. The current study aimed to investigate the biological and clinical role of ribonucleotide reductase subunit M2 (RRM2), a key enzyme regulating the dNTP pool, in clear-cell renal cell carcinoma (ccRCC).

Methods: The expression of RRM2 on disease progression and patient outcome was assessed in ccRCC. Then, the effect of RRM2 inhibition on renal cell carcinoma (RCC) growth using siRNA or Triapine, an RRM2-specific inhibitor, was characterized in RCC cell lines.

Results: The expression of RRM2 was up-regulated in ccRCC tissues as compared to the normal tissues. Patients with high RRM2 expression tend to have advanced pT stages, high Fuhrman grades, and shortened overall survival (OS). RRM2-siRNAs or Triapine significantly inhibited the cell growth by inducing G0/G1 cell cycle arrest in RCC cells through the attenuation of dNTP pool.

Conclusions: The current results provided evidence that RRM2 might act as a novel target for ccRCC, and exploration of nonnucleoside, reversible, small-molecule inhibitors against RRM2 could be promising.

Keywords: clear-cell renal cell carcinoma, RRM2, targeted therapy

\section{Introduction}

Clear-cell renal cell carcinoma (ccRCC) is the most common histological subtype of renal cell carcinoma, accounting for almost $80 \%$ of all the kidney cancers. ${ }^{1}$ Approximately, $30 \%$ of the patients were diagnosed with advanced or metastatic disease at the first visit to the hospital. ${ }^{2}$ Although targeted therapies that inhibit the vascular endothelial growth factor (VEGF) and mammalian target of rapamycin (mTOR) pathways have achieved considerable clinical responses and improve the progression-free survival (PFS) and overall survival (OS) of RCC patients, their efficiencies are palliative. Hence, the novel therapeutic strategy is an urgent requisite.

Ribonucleotide reductase (RNR) is an enzyme that catalyzes the rate-limiting step of de novo biosynthesis of dNTPs, which plays a critical role in genome maintenance. $^{3,4}$ Mammalian RNR consist of two homodimeric subunits, the large catalytic dimer RRM1 and the small regulatory dimer RRM2 or p53R2. Unlike RRM1 and p53R2 remains constant throughout the cell cycle, the expression of RRM2 is cell cycle dependent. ${ }^{5}$ RRM1 acts as a tumor suppressor in different types of cancer, and is involved in tumor growth, metastasis, and drug resistance. ${ }^{6-9}$ While RRM2 has oncogenic activity, it is overexpressed in a variety of human cancers, such as gastric carcinoma, ${ }^{10}$ bladder cancer, ${ }^{11}$ 
melanoma, ${ }^{12}$ epithelial ovarian cancer, ${ }^{13}$ nasopharyngeal carcinoma, ${ }^{14}$ and colorectal cancer. ${ }^{15}$ RRM2 may serve as a prognostic biomarker for the prediction of survival and a potential target for therapy in patients with these cancers. However, the role of RRM 2 in ccRCC remains poorly understood.

This study aims to characterize the biological and clinical significance of RRM2 in ccRCC pathogenesis and to implore the therapeutic potential of targeting RRM2 using siRNA or RRM2-specific inhibitor Triapine (3-AP).

\section{Materials and methods}

\section{Tissue specimens}

The clinical samples, consisting of 90 ccRCC tissues and 30 noncancerous tissues, were collected from the Department of Urology, Shanghai Ninth People's Hospital, Shanghai Jiao Tong University School of Medicine (Shanghai, China) between 2005 and 2010. Each of the samples was cut into two sections. One section was stored at $-80{ }^{\circ} \mathrm{C}$ prior to RNA extraction, after incubating in an RNAlater solution (AM7021, Ambion Life Technologies, USA) overnight at $4{ }^{\circ} \mathrm{C}$, while another was fixed in formalin for the immunohistochemistry (IHC) assay. The patients were followed up from the day of surgery to the day of death or last examination, which was assessed as OS. The median follow-up time was 60 (range, 3-83) months. The clinical samples and data were collected in accordance with the Declaration of Helsinki after obtaining the written informed consent. The protocol was approved by the Ethics Committee of Shanghai Ninth People's Hospital, Shanghai Jiao Tong University School of Medicine.

\section{RT-qPCR analysis}

Total RNA was isolated from human ccRCC tissues or noncancerous tissues using TRIzol reagent (Invitrogen Life Technologies, USA). The reverse transcription of the total RNA was carried out using the QuantiTect Reverse Transcription Kit (QIAGEN, Germany), and the real-time quantity PCR was performed using SYBR Green PCR Master Mix (Applied Biosystems, USA) according to the manufacturer's instruction on the ViiA 7 Real-Time PCR System (Applied Biosystems, USA). The expression of the target gene was normalized against that of an internal control $\beta$-actin. The sequences of primers used for RTqPCR analysis were as follows:
RRM2: 5'-AGACTTATGCTGGAACTG-3' and 5'TCTGATACTCGCCTACTC-3';

$\beta$-actin: 5'-CATGTACGTTGCTATCCAGGC-3' and 5'CTCCTTAATGTCACGCACGAT-3'.

\section{IHC analysis}

Formalin-fixed tissues were embedded with paraffin, cut into 5- $\mu \mathrm{m}$ sections, and mounted onto slides. The sections were deparaffinized at $58{ }^{\circ} \mathrm{C}$ for $2-3 \mathrm{~h}$, followed by dewaxing in xylene and rehydrating through a gradient of alcohol to distilled water. After blocking endogenous peroxidase activity in 3\% hydrogen peroxide for $15 \mathrm{~min}$ at room temperature, the sections were subjected to antigen retrieval in a pressure cooker at $150{ }^{\circ} \mathrm{C}$ for $5-10 \mathrm{~min}$. Then, the sections were incubated with the anti-RRM2 antibody (ab57653; Abcam) at a dilution of 1:200 at $4^{\circ}$ $\mathrm{C}$ overnight and immunoglobulin-G-horseradish peroxidase secondary antibody at $37{ }^{\circ} \mathrm{C}$ for $30 \mathrm{~min}$. Subsequently, the sections were stained with 3, 3-diaminobenzidine (DAB) for $2 \mathrm{~min}$ and counter-stained with hematoxylin, followed by visualizing under a microscope.

Immunostaining results were estimated by the mean score of five random fields of vision at high $(\times 400)$ magnification for each slide. The immunoreactivity score (IRS) was calculated as follows: intensity score $\times$ positive staining score. The staining intensity was scored as follows: 0 (negative), 1 (weak staining), 2 (moderate staining) or 3 (strong staining). The positive staining was scored as follows: 0 ( $0 \%$ positive cells), 1 ( $0-10 \%$ positive cells), 2 (10-50\% positive cells), 3 (50-80\% positive cells) or 4 $(>80 \%$ positive cells). The scoring was confirmed by two pathologists in a double blind model. An optimal cut-off value for RRM2 expression was classified as follows: IRS $<6$, low expression; IRS $\geq 6$, high expression.

\section{Cell lines and inhibitors}

The human RCC cell lines 786-O and 769-P were purchased from the American Type Culture Collection (ATCC). All cells were maintained in RPMI 1640 medium, supplemented with $10 \%$ fetal bovine serum at $37^{\circ} \mathrm{C}$ in a humidified environment with $5 \% \mathrm{CO}_{2}$. A small molecular inhibitor Triapine (3-AP) was obtained from Selleck (Texas, USA), solubilized in dimethyl sulfoxide (DMSO) as a $10 \mathrm{mM}$ stock solution and stored at $-20{ }^{\circ} \mathrm{C}$.

\section{siRNA transfection}

Tumor cells were seeded in 96-well or 6-well plate at $50-60 \%$ confluency overnight, followed by transfection 
with a specific siRNA duplex for $48 \mathrm{~h}$ using Lipofectamine RNAiMAX Transfection Reagent (Invitrogen) according to the manufacturer's protocol. A nonspecific oligonucleotide not complementary to any human gene was used as a negative control (NC). siRNAs were purchased from Gene Pharma (Shanghai, China). The sequences were as follows:

siRRM2 \#1: 5'-CCCAUCGAGUACCAUGAUATT-3'; siRRM2 \#2: 5'-CGUCGAUAUUCUGGCUCAATT-3'.

\section{Western blotting}

Protein extraction and Western blot analysis were performed according to the procedures described previously. ${ }^{16}$ Briefly, the proteins of the cells on the membrane were incubated with a primary mouse monoclonal antibody against human RRM2 (1:1000 dilution; ab57653; Abcam) at $4{ }^{\circ} \mathrm{C}$ overnight. The mouse monoclonal antibody against human $\beta$-actin (1:5000 dilution; ab6276; Abcam) was used as a control.

\section{Cell proliferation assay}

Cells were seeds in 96-well plates at a plating density of 3000 cells per well in six replicates, incubating at $37^{\circ} \mathrm{C}$ overnight. After transfection with siRNAs targeting RRM2 or treatment with Triapine for the indicated time, $10 \mu \mathrm{L}$ of CCK-8 solution (Life Technologies) was added to each well, incubating for $1-2 \mathrm{~h}$ at $37^{\circ} \mathrm{C}$. Then the optical density (OD) value was read at $450 \mathrm{~nm}$ on an ELISA plate reader. Cell viability rate was calculated as OD (treated)/OD (control) $\times 100 \%$.

\section{Cell cycle analysis}

After transfection with siRNAs targeting RRM2 or treatment with Triapine for $48 \mathrm{~h}$, at least $1 \times 10^{6}$ tumor cells were harvested and fixed with $70 \%$ ethanol at $-20{ }^{\circ} \mathrm{C}$ for $24 \mathrm{~h}$. Then, the cell pellets were stained with propidium iodide (PI) (Sigma-Aldrich, USA) and RNase A, incubating in the dark at room temperature for $30 \mathrm{~min}$. PI fluorescence signals were assessed on a FACScan flow cytometer (FACS Canto II, BD). The cell cycle distribution was analyzed using the Mod Fit software.

\section{dNTP detection}

After transfection with siRNAs targeting RRM2 for $72 \mathrm{~h}$, the intracellular metabolites were extracted using $1 \mathrm{~mL}$ of cold MeOH:ACN:H2O (2:2:1, v/v) solvent mixture in liquid nitrogen for $1 \mathrm{~min}$. The dried supernatant was stored at $-80{ }^{\circ} \mathrm{C}$, followed by centrifugation at $14,000 \times g$ for $15 \mathrm{~min}$ at $4{ }^{\circ} \mathrm{C}$. LC-MS/MS analysis was performed using a triple quadrupole mass spectrometry (QqQ-MS) coupled to a Dionex Ultimate 3000 UHPLC system (Thermo Fisher Scientific, USA). The chromatographic separation of samples was performed on an Agilent 1260 HPLC system (Agilent Technologies) with a SeQuant ZIC pHILIC column (Merck) and a SeQuant ZIC pHILIC guard column (Merck) at $250 \mu \mathrm{L} / \mathrm{min}$ flow rate. The mass spectrometer was operated in a reaction monitoring (SRM) mode referring to the literature. ${ }^{17}$

\section{Cell apoptosis analysis}

After treatment with the indicated concentration of Triapine for $72 \mathrm{~h}$, at least $1 \times 10^{6}$ tumor cells were collected and evaluated using the Annexin V-FITC Apoptosis Detection kit (BD Pharmingen, Germany) according to the manufacturer's instructions. Cells were analyzed on a FACSCalibur (BD Biosciences, Germany). The percentage of apoptotic cells was calculated using the FlowJo software.

\section{Statistical analysis}

Statistical analysis was performed by SPSS 21.0 (SPSS Inc., Chicago, IL, USA). The differences between groups were assessed using the two-tailed Student's t-tests. The correlation between the clinicopathological features of ccRCC and RRM2 was analyzed using either a chisquare test or Fisher's exact test. The survival curves were plotted using the Kaplan-Meier method and compared using a log-rank test. The effect of any prognostic factor on OS was analyzed by univariate and multivariate Cox regression model. Every in vitro experiment was repeated at least three times. The results are presented as mean \pm standard deviation (SD). The comparison between the groups was carried out by a $t$-test. $P<0.05$ was considered as statistically significant.

\section{Results}

\section{RRM2 is upregulated in ccRCC tissues}

In order to probe the role of RRM2 in ccRCC, we first examined the mRNA level of RRM2 in tissues from 10 cases of ccRCC and the corresponding normal renal tissues by RT-qPCR analysis. As shown in Figure 1A, the RRM2 mRNA level in ccRCC tissues was significantly higher than that in the corresponding normal renal tissues $(P<0.01)$. Next, we examined the protein level of RRM2 in 90 cases of ccRCC tissues and 30 cases of normal renal tissues by IHC. As shown in Figure 1B, RRM2 protein was localized 
A

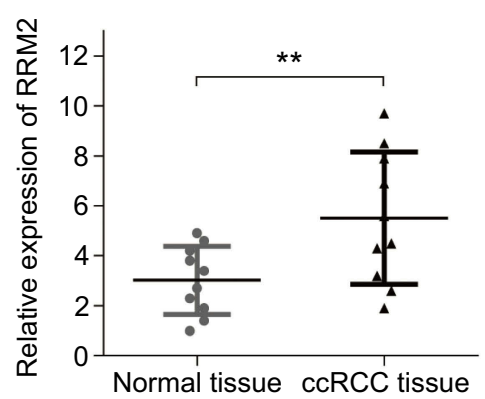

C

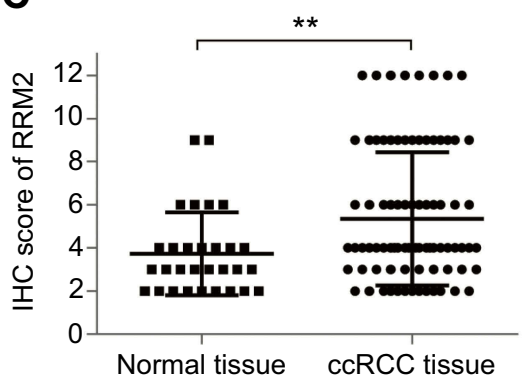

B

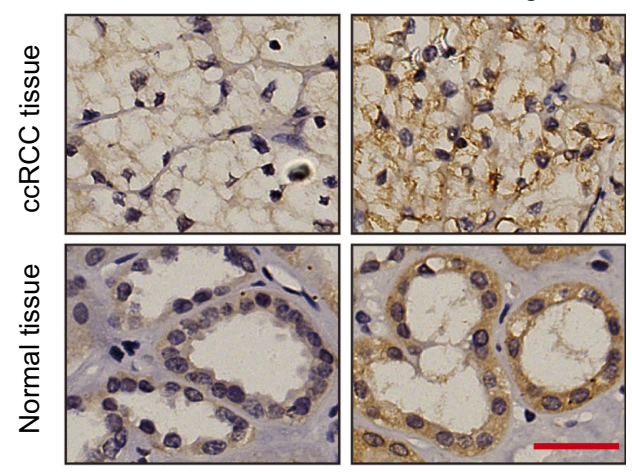

D

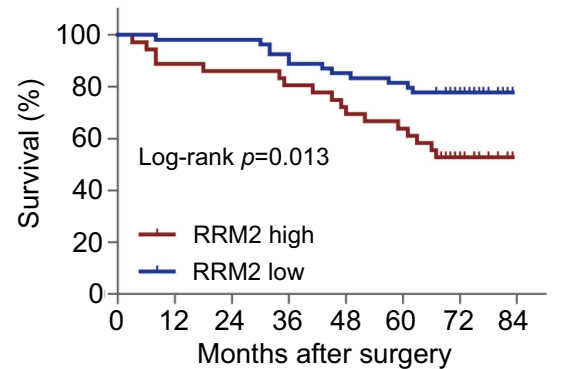

Figure I RRM2 is upregulated in ccRCC and predicts poor prognosis. (A) The mRNA level of RRM2 in tissues from 10 cases of ccRCC and the corresponding normal renal tissues was examined using RT-qPCR analysis. $* * P<0.01$. (B) IHC staining was performed in 90 cases of ccRCC tissues and 30 cases of normal renal tissues. The representative images of RRM2 expression in the cell cytoplasm are shown ( $\times 400)$. The scale bar represents $50 \mu \mathrm{m}$. (C) The IHC score of RRM2 in the above samples. ** $P<0.01$. (D) Survival analysis of RCC patients related to RRM2 expression was analyzed by Kaplan-Meier survival curves.

Abbreviations: ccRCC, clear-cell renal cell carcinoma; IHC, immunohistochemistry; RRM2, ribonucleotide reductase subunit M2.

in the cell cytoplasm. In comparison to the normal renal tissues, the protein level of RRM2 in ccRCC tissues was significantly higher $(P<0.01$; Figure $1 \mathrm{C}$; Table 1$)$. In conclusion, the level of RRM2 was upregulated in ccRCC as compared to that in the noncancerous tissues.

\section{Association of RRM2 expression with clinicopathological characteristics of ccRCC patients}

The clinicopathological characteristics of 90 patients included in this study were summarized in Table 2 . In order to analyze the association between the RRM2 expression and

Table I Expression of RRM2 in ccRCC and normal tissues

\begin{tabular}{|l|l|l|l|l|}
\hline \multirow{2}{*}{$\begin{array}{l}\text { Tissue } \\
\text { sample }\end{array}$} & \multirow{2}{*}{$\begin{array}{l}\text { No. of } \\
\text { patients }\end{array}$} & \multicolumn{2}{|l|}{ RRM2 } & \multirow{2}{*}{-value } \\
\cline { 3 - 4 } & & $\begin{array}{l}\text { Low, n } \\
\text { (\%) }\end{array}$ & $\begin{array}{l}\text { High, } \mathbf{n} \\
\text { (\%) }\end{array}$ & \\
\hline ccRCC tissue & 90 & $54(60.0)$ & $36(40.0)$ & 0.007 \\
Normal tissue & 30 & $26(86.7)$ & $4(13.3)$ & \\
\hline
\end{tabular}

Abbreviations: ccRCC, clear-cell renal cell carcinoma; RRM2, ribonucleotide reductase subunit $M 2$. clinicopathological characteristics of patients with ccRCC, patients were segregated into two groups according to the cutoff value of RRM2 expression in tumor tissue samples. High RRM2 expression was observed in $36 / 90$ (40.0\%) of the ccRCC tissue samples. We found that patients with high RRM2 expression tended to have advanced pT stages $(P<0.001$; Table 2$)$ and high Fuhrman grades $(P=0.008$; Table 2) as compared to those patients with low RRM2 expression. However, no significant correlation was detected between the RRM2 expression and other clinicopathological features, including age, gender, $\mathrm{pN}$, and $\mathrm{pM}$ stages $(P>0.05$; Table 2).

\section{Overexpression of RRM2 predicts poor prognosis in $\mathrm{ccRCC}$ patients}

In order to estimate the prognostic role of RRM2 in patients with ccRCC, Kaplan-Meier curves followed by a log-rank test analysis were evaluated between patients with high and low RRM2 expression. The median follow-up time was 60 months. The cumulative five-year OS in high RRM2 expression patients was $52.8 \%$, which was significantly worse than $77.8 \%$ in the low RRM2 expression group 
Table 2 Association of RRM2 expression with clinicopathologic characteristics in ccRCC

\begin{tabular}{|c|c|c|c|c|}
\hline \multirow[t]{2}{*}{ Variables } & \multirow{2}{*}{$\begin{array}{l}\text { No. of } \\
\text { patients }\end{array}$} & \multicolumn{2}{|l|}{ RRM2 } & \multirow[t]{2}{*}{$p$-value } \\
\hline & & $\begin{array}{l}\text { Low, n } \\
\text { (\%) }\end{array}$ & $\begin{array}{l}\text { High, n } \\
\text { (\%) }\end{array}$ & \\
\hline \multicolumn{5}{|l|}{ Gender } \\
\hline Male & 51 & $33(64.7)$ & I8 (35.3) & 0.297 \\
\hline Female & 39 & $21(53.8)$ & $18(46.2)$ & \\
\hline \multicolumn{5}{|l|}{ Age (year) } \\
\hline$\leq 55$ & 38 & $23(60.5)$ & 15 (39.5) & 0.931 \\
\hline$>55$ & 52 & 31 (59.6) & $21(40.4)$ & \\
\hline \multicolumn{5}{|l|}{ pT stage } \\
\hline TI & 64 & $49(76.6)$ & $15(23.4)$ & $<0.001$ \\
\hline $\mathrm{T} 2$ & 21 & $4(19.0)$ & I7 (8I.0) & \\
\hline $\mathrm{T} 3+\mathrm{T} 4$ & 5 & I (20.0) & $4(80.0)$ & \\
\hline \multicolumn{5}{|l|}{$\mathrm{pN}$ stage } \\
\hline No & 89 & $53(59.6)$ & $36(40.4)$ & 1.000 \\
\hline $\mathrm{NI}$ & I & I (I00.0) & $0(0.0)$ & \\
\hline \multicolumn{5}{|l|}{ PM stage } \\
\hline MO & 88 & $53(60.2)$ & 35 (39.8) & 1.000 \\
\hline MI & 2 & I (50.0) & I (50.0) & \\
\hline \multirow{2}{*}{\multicolumn{5}{|c|}{$\begin{array}{l}\text { Fuhrman } \\
\text { grade }\end{array}$}} \\
\hline & & & & \\
\hline$|+| \mid$ & 75 & $50(66.7)$ & $25(33.3)$ & 0.008 \\
\hline III+IV & 15 & $4(26.7)$ & II (73.3) & \\
\hline
\end{tabular}

Abbreviations: ccRCC, clear-cell renal cell carcinoma; $\mathrm{pT}$, pathological tumor; $\mathrm{pN}$, pathological lymph node; $\mathrm{PM}$, pathological metastasis; RRM2, ribonucleotide reductase subunit M2.

( $P=0.013$; Figure 1D). Moreover, univariate Cox regression analysis showed that RRM2 expression together with age, pTNM stages, and Fuhrman grades significantly correlated with the OS of patients with ccRCC $(P<0.001$; Table 3$)$. Multivariate analysis indicated that age, pTNM stages, and Fuhrman grades were independent prognostic factors for OS of ccRCC patients $(P<0.001$; Table 3$)$. On the other hand, the RRM2 expression did not appear to be an independent factor ( $P=0.624$; Table 3). Therefore, the prognostic role of RRM2 in patients with ccRCC may be related to $\mathrm{pT}$ stages and Fuhrman grades.

\section{Knockdown of RRM2 inhibits the proliferation and induces G0/GI arrest in RCC cells through attenuation of dNTP pool}

To further investigate the role of RRM2 in RCC cells, two specific siRNAs targeting RRM2 were transfected into
786-O and 769-P cells to knockdown the expression of RRM2. Then the proliferation and cell cycle distribution of RCC cells were analyzed. As shown in Figure 2A, two siRNA sense strands decreased the level of RRM2 protein as compared to the non-specific oligonucleotide. After the CCK-8 assay, the knockdown of RRM2 significantly inhibited the cell proliferation in both 786-O and 769-P cells at 24, 48, and $72 \mathrm{~h}$ (Figure 2B). In addition, the knockdown of RRM2 also significantly induced G0/G1 cell cycle arrest by propidium iodide (PI) staining (Figure 2C). Furthermore, the intracellular RRM2 activity is cell cycle dependent in mammalian cells, with activities rising at the border of $\mathrm{G} 1$ to $\mathrm{S}$ phase transition, which contributes to the dNTP pool expansion during the $S$ phase. ${ }^{18}$ Herein, we demonstrated that knockdown of RRM2 led to the depletion of the dNTP pool, as indicated by a decrease in a specific dNTP: dATP and dGTP (Figure 2D). These results indicated that the knockdown of RRM2 inhibits the proliferation and induces the G0/G1 arrest in RCC cells via attenuation of the dNTP pool.

\section{RRM2 inhibitor reduces the viability of} RCC cells by inducing the G0/GI arrest

To further assess the antitumor efficacy of targeting RRM2 on RCC, an RRM2-specific inhibitor Triapine (3-AP) was examined on 786-O and 769-P cells. It was reported to be effective in two clinical studies on cervical cancer ${ }^{19}$ and currently assessed in several phase I and II trials in other cancer types. The tumor cells were treated with $0.5,1$, and $2 \mu \mathrm{M}$ of Triapine or the same dose of DMSO for 24,48 , and $72 \mathrm{~h}$ respectively. As a result, Triapine significantly decreased the cell viability of both $786-\mathrm{O}$ and $769-\mathrm{P}$ cells in a dose- and time-dependent manner (Figure 3A). Moreover, both 786-O and 769-P cells showed significant G0/G1 cell cycle arrest after treatment with Triapine (Figure 3B). Conversely, the percentage of apoptotic cells between any groups was not significantly different (Figure 3C). These results suggested that RRM2 may act as a novel therapeutic target for RCC.

\section{Discussion}

Renal cell carcinoma is essentially a metabolic disease. ${ }^{20}$ To date, a large number of studies have identified the risk of RCC in disease states with known metabolic links, 
Table 3 Univariate and multivariate Cox regression analysis for overall survival in ccRCC

\begin{tabular}{|c|c|c|c|c|c|c|}
\hline \multirow[t]{2}{*}{ Variables } & \multicolumn{3}{|c|}{ Univariate analysis } & \multicolumn{3}{|c|}{ Multivariate analysis } \\
\hline & HR & $95 \% \mathrm{Cl}$ & $p$-value & HR & $95 \% \mathrm{Cl}$ & $p$-value \\
\hline $\begin{array}{l}\text { Gender } \\
\text { Male } \\
\text { Female } \\
\text { Age (year) }\end{array}$ & $\begin{array}{l}1 \\
0.951\end{array}$ & $0.867-1.042$ & 0.283 & & & \\
\hline $\begin{array}{c}\quad \leq 55 \\
\quad>55 \\
\text { PT stage }\end{array}$ & $\begin{array}{l}\mathrm{I} \\
\mathrm{I} .044\end{array}$ & $1.039-1.048$ & $<0.001$ & 1.060 & $1.055-1.065$ & $<0.001$ \\
\hline $\begin{array}{r}\mathrm{TI}+\mathrm{T} 2 \\
\mathrm{~T} 3+\mathrm{T} 4 \\
\mathrm{pN} \text { stage }\end{array}$ & $\begin{array}{l}1 \\
8.328\end{array}$ & $7.264-9.548$ & $<0.001$ & $\begin{array}{l}\text { I } \\
8.437\end{array}$ & $6.903-10.313$ & $<0.001$ \\
\hline $\begin{array}{c}\text { No } \\
\text { NI } \\
\text { pM stage }\end{array}$ & $\begin{array}{l}1 \\
20.551\end{array}$ & $15.696-26.909$ & $<0.001$ & $\begin{array}{l}\text { I } \\
16.840\end{array}$ & $|2.482-22.72|$ & $<0.001$ \\
\hline $\begin{array}{l}\text { MO } \\
\text { MI }\end{array}$ & $\begin{array}{l}1 \\
13.760\end{array}$ & $11.246-16.837$ & $<0.001$ & $\begin{array}{l}\mathrm{I} \\
1.705\end{array}$ & $1.282-2.268$ & $<0.001$ \\
\hline Fuhrman grade & & & & & & \\
\hline $\begin{array}{c}\text { I + II } \\
\text { III+IV } \\
\text { RRM2 expression }\end{array}$ & $\begin{array}{l}\text { I } \\
5.523\end{array}$ & $5.025-6.086$ & $<0.001$ & 4.138 & $3.698-4.631$ & $<0.001$ \\
\hline $\begin{array}{l}\text { Low } \\
\text { High }\end{array}$ & $\begin{array}{l}1 \\
2.254\end{array}$ & $2.055-2.47 \mid$ & $<0.001$ & $\begin{array}{l}1 \\
1.036\end{array}$ & $0.901-1.191$ & 0.624 \\
\hline
\end{tabular}

Abbreviations: ccRCC, clear-cell renal cell carcinoma; $\mathrm{pT}$, pathological tumor; pN, pathological lymph node; pM, pathological metastasis; RRM2, ribonucleotide reductase subunit M2.

including body mass index, obesity, diabetes, and atherosclerosis. ${ }^{21}$ It is clear that metabolic alteration is a primary feature for tumorigenesis, which not only meets the increased anabolic requirements for proliferating or dividing but also influences cellular differentiation. Hence, the alteration of metabolic factors may indicate new directions for therapy, diagnosis, or prognosis. More than $80 \%$ of ccRCC harbors the VHL gene mutation or methylation inactivation, which regulates the metabolic alteration through the hypoxia-inducible factor (HIF) pathway. ${ }^{22,23}$ In some cases, the alterations arise from changes in the oncogenic metabolism enzymes. ${ }^{24}$ For example, stearoyl-CoA desaturase 1 (SCD1) was overexpressed in all the stages of ccRCC. The genetic knockdown or pharmacological inhibition of SCD1 decreased the proliferation of RCC cells. ${ }^{25}$

Sufficient supply of dNTPs is required for the uncontrolled replication of cancers, which is a defining feature. As a key enzyme regulating the dNTP pool, RRM2 exhibits a crucial role in tumor cell division, proliferation, differentiation and invasion. ${ }^{5,26}$ Increased RRM2 expression is correlated with malignant transformation and tumor cell growth, which could act as a prognostic biomarker of colorectal cancer (CRC). ${ }^{15}$ In the present study, we demonstrated that the overexpression of RRM2 in ccRCC is significantly associated with advanced $\mathrm{pT}$ stages and high Fuhrman grades in patients. Due to the correlation of RRM2 with the prognostic factors of pT stages and Fuhrman grades, RRM2 could predict a short OS of RCC patients, but it was not an independent prognostic factor. Similarly, in glioma patients, RRM2 is a negative prognostic factor that worsens the survival and is correlated with the malignancy degree as defined by WHO. ${ }^{27}$

In the present study, both genetic and pharmacological inhibition of RRM2 in RCC cells significantly decreased tumor cell proliferation by inducing the G0/ G1 cell cycle arrest. Consistent with this phenomenon, RRM2-siRNAs or RRM2 inhibitor significantly represses the cell viability by inducing cell-cycle arrest at the $\mathrm{G} 0 / \mathrm{G} 1$ phase in glioblastoma, ${ }^{28}$ neuroblastoma, ${ }^{29}$ primary effusion lymphoma, ${ }^{30}$ 
A

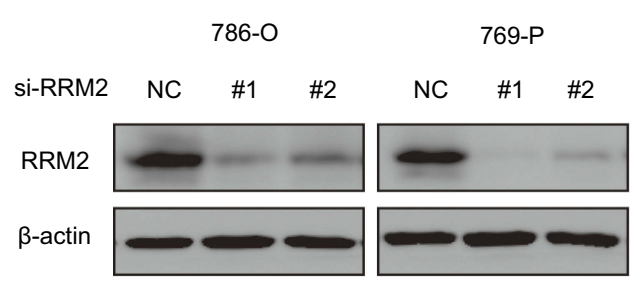

C
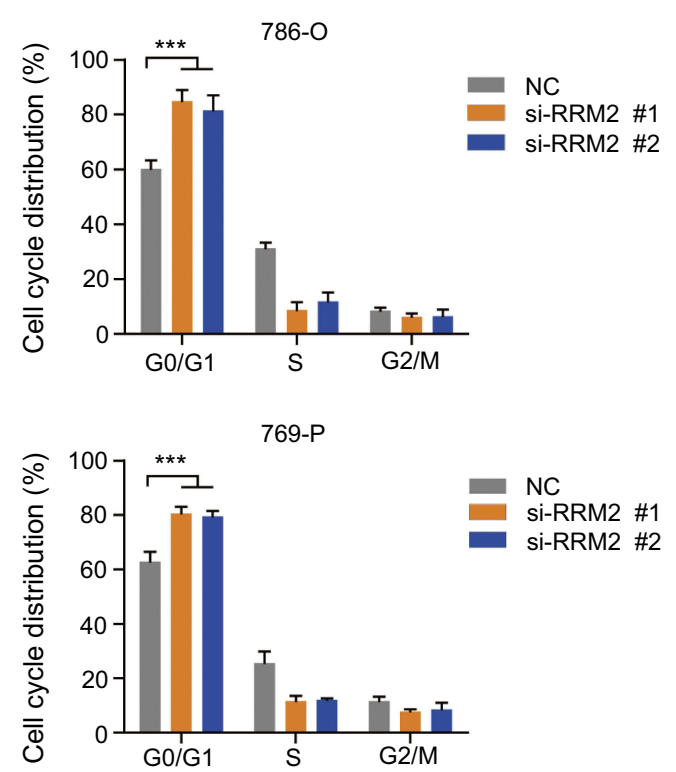

B

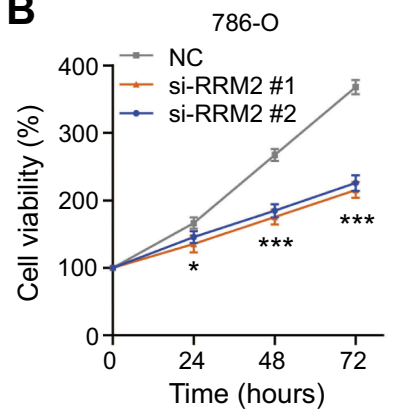

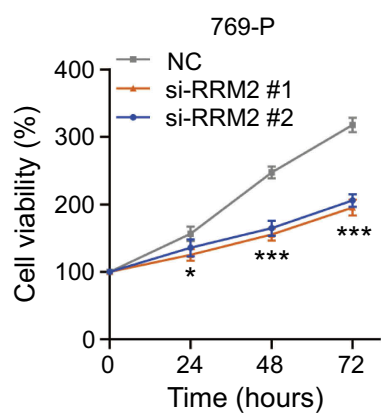

D
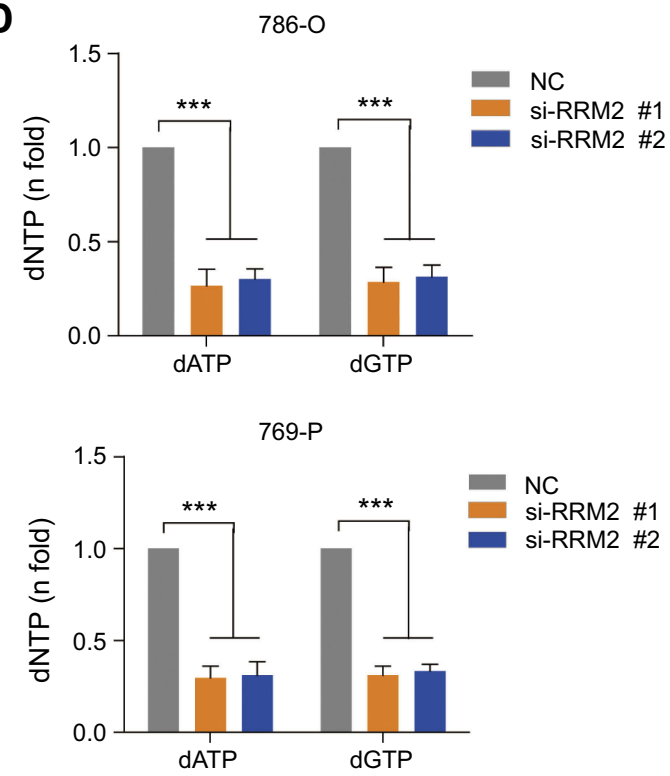

Figure 2 Knockdown of RRM2 inhibits the proliferation and induces G0/GI arrest in RCC cells through attenuation of the dNTP pool. (A) Western blotting showed that knockdown of RRM2 using siRNAs could effectively decrease the protein expression of RRM2 in 786-O and 769-P cells. (B) The proliferation assay showed that the viability of 786-O and 769-P cells was significantly decreased by the knockdown of RRM2. $* P<0.05$; *** $P<0.001$. (C) Flow cytometry showed that the knockdown of RRM2 induced G0/GI arrest in 786-O and 769-P cells. *** P<0.00I. (D) LC-MS/MS analysis showed that the knockdown of RRM2 significantly decreased the dNTP pool, individually dATP and dGTP, in 786-O and 769-P cells. $* * * P<0.001$.

Abbreviations: NC, negative control; RRM2, ribonucleotide reductase subunit M2.

adrenocortical cancer, ${ }^{31}$ or at the sub G0/G1 phase in melanoma. ${ }^{32}$ However, the role of RRM2 may differ in different types of cancers. RRM2-siRNAs dramatically decreased the formation of cell colonies by inducing the significant cell-cycle arrest at the $\mathrm{S}$ phase in pancreatic cancer. ${ }^{33}$ In addition, the inhibition of RRM2 regulates the RCC cell growth and cell cycle transition through the attenuation of dNTP pool. These results suggested that RRM2 might function as a tumor promoter in human ccRCC, which could be a novel target for patients with ccRCC. Due to the cytotoxicity of nucleoside analogs such as gemcitabine and clofarabine, the exploration of nonnucleoside, reversible, small-molecule inhibitors against RRM2, such as Triapine, could be promising.

\section{Conclusion}

In summary, the current study indicated that RRM2 plays a tumor-promoting role in human ccRCC. As a potential target for ccRCC, the exploration of nonnucleoside, reversible, small-molecule inhibitors against RRM2, could be promising.

\section{Acknowledgments}

This work was sponsored by the National Natural Science Foundation of China (No. 81802517); the Integrated Traditional Chinese and Western Medicine of Shanghai (ZHYY-ZXYJHZX-1-03); Clinical Research Program of 9th People's Hospital, Shanghai Jiao Tong University School of Medicine (JYLJ005); 
A

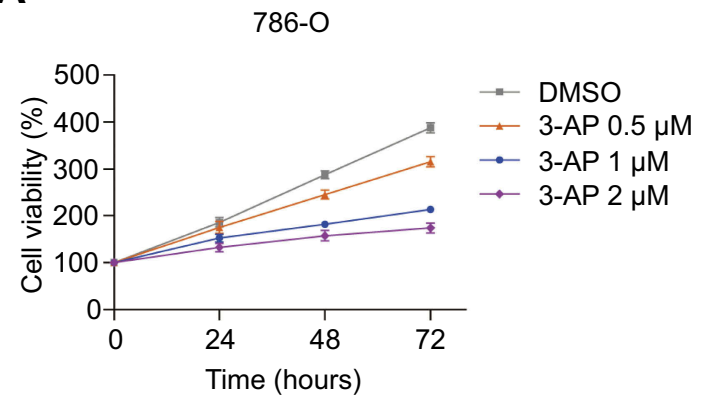

B

786-O

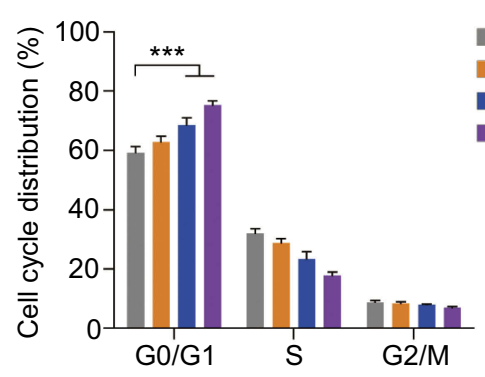

C

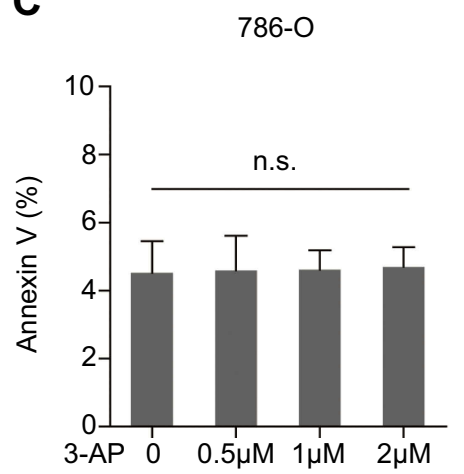

769-P

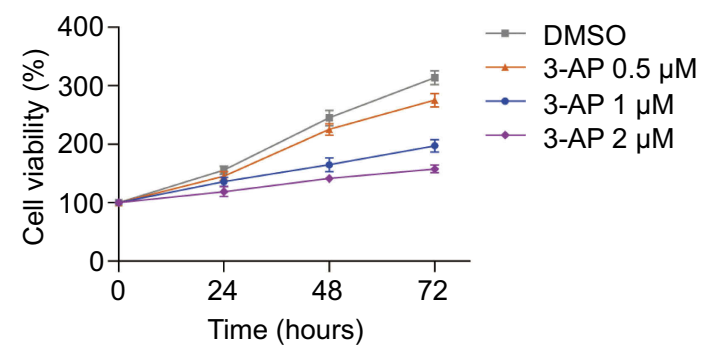

769-P

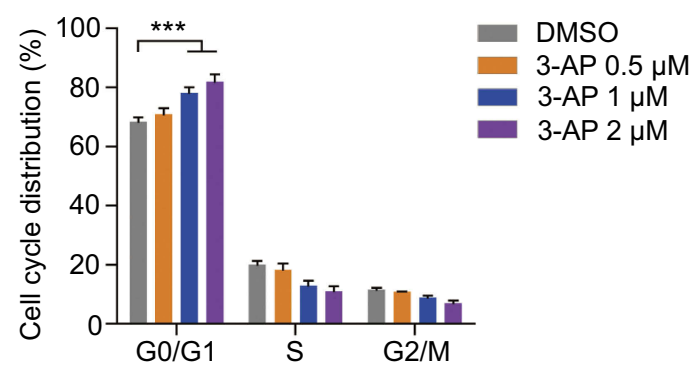

769-P

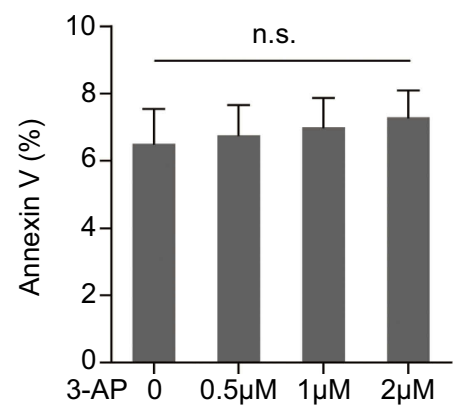

Figure 3 RRM2 inhibitor reduces the viability of RCC cells by inducing the G0/GI arrest. (A) 786-O and 769-P cells were treated with 0.5 , I, or $2 \mu M$ Triapine for 24 , 48 , and 72 hours respectively. The cell viability was assessed by CCK-8 assay. (B) 786-O and 769-P cells were treated with 0.5 , I, or $2 \mu \mathrm{M}$ Triapine respectively, for 48 hours. The cell cycle distribution was detected by PI staining and shown in the bar graph as percentages of cells. Error bars represent the mean \pm SD of three independent experiments. $* * * P<0.00 \mathrm{I}$. (C) $786-\mathrm{O}$ and $769-\mathrm{P}$ cells were treated with 0.5 , I, or $2 \mu \mathrm{M}$ Triapine, respectively, for 72 hours. Apoptotic cells were detected by $\mathrm{Pl} /$ Annexin $\mathrm{V}$ dual staining and shown in the bar graph as percentages of cells. Error bars represent mean $\pm \mathrm{SD}$ of three independent experiments.

Abbreviations: n.s., not significant; PI, propidium iodide; RCC, renal cell carcinoma; RRM2, ribonucleotide reductase subunit M2.

and Program for Outstanding Medical Academic Leader.

\section{Disclosure}

The authors report no conflicts of interest in this work.

\section{References}

1. Rini BI, Campbell SC, Escudier B. Renal cell carcinoma. Lancet. 2009;373(9669):1119-1132. doi:10.1016/S0140-6736(09)60229-4

2. Fisher R, Gore M, Larkin J. Current and future systemic treatments for renal cell carcinoma. Semin Cancer Biol. 2013;23(1):38-45. doi:10.1016/j.semcancer.2012.06.004
3. Kolberg M, Strand KR, Graff P, Andersson KK. Structure, function, and mechanism of ribonucleotide reductases. Biochim Biophys Acta. 2004;1699(1-2):1-34. doi:10.1016/j.bbapap.2004.02.007

4. Stubbe J. Ribonucleotide reductases in the twenty-first century. Proc Natl Acad Sci U S A. 1998;95(6):2723-2724.

5. Aye Y, Li M, Long MJ, Weiss RS. Ribonucleotide reductase and cancer: biological mechanisms and targeted therapies. Oncogene. 2015;34(16):2011-2021. doi:10.1038/onc.2014.155

6. Jordheim LP, Seve P, Tredan O, Dumontet C. The ribonucleotide reductase large subunit (RRM1) as a predictive factor in patients with cancer. Lancet Oncol. 2011;12(7):693-702. doi:10.1016/S14702045(10)70244-8

7. Gautam A, Li ZR, Bepler G. RRM1-induced metastasis suppression through PTEN-regulated pathways. Oncogene. 2003;22 (14):2135-2142. doi:10.1038/sj.onc. 1206232 
8. Zheng Z, Chen T, Li X, Haura E, Sharma A, Bepler G. DNA synthesis and repair genes RRM1 and ERCC1 in lung cancer $N$ Engl J Med. 2007;356(8):800-808. doi:10.1056/NEJMoa065411

9. Akita H, Zheng Z, Takeda Y, et al. Significance of RRM1 and ERCC1 expression in resectable pancreatic adenocarcinoma. Oncogene. 2009;28(32):2903-2909. doi:10.1038/onc.2009.158

10. Morikawa T, Hino R, Uozaki H, et al. Expression of ribonucleotide reductase M2 subunit in gastric cancer and effects of RRM2 inhibition in vitro. Hum Pathol. 2010;41(12):1742-1748. doi:10.1016/j. humpath.2010.06.001

11. Morikawa T, Maeda D, Kume H, Homma Y, Fukayama M. Ribonucleotide reductase M2 subunit is a novel diagnostic marker and a potential therapeutic target in bladder cancer. Histopathology. 2010;57(6):885-892. doi:10.1111/j.1365-2559.2010.03725.x

12. Zuckerman JE, Hsueh T, Koya RC, Davis ME, Ribas A. siRNA knockdown of ribonucleotide reductase inhibits melanoma cell line proliferation alone or synergistically with temozolomide. J Invest Dermatol. 2011;131(2):453-460. doi:10.1038/jid.2010.310

13. Aird KM, Li H, Xin F, Konstantinopoulos PA, Zhang R. Identification of ribonucleotide reductase $\mathrm{M} 2$ as a potential target for pro-senescence therapy in epithelial ovarian cancer. Cell Cycle. 2014;13(2):199-207. doi:10.4161/cc.26953

14. Han P, Lin ZR, Xu LH, et al. Ribonucleotide reductase M2 subunit expression and prognostic value in nasopharyngeal carcinoma. Mol Med Rep. 2015;12(1):401-409. doi:10.3892/mmr.2015.3360

15. Hsieh YY, Chou CJ, Lo HL, Yang PM. Repositioning of a cyclin-dependent kinase inhibitor GW8510 as a ribonucleotide reductase M2 inhibitor to treat human colorectal cancer. Cell Death Discov. 2016;2:16027. doi:10.1038/cddiscovery.2016.9

16. Zou Y, Wang J, Leng X, et al. The selective MEK1 inhibitor Selumetinib enhances the antitumor activity of everolimus against renal cell carcinoma in vitro and in vivo. Oncotarget. 2017;8 (13):20825-20833. doi:10.18632/oncotarget.15346

17. Qu J, Sun W, Zhong J, et al. Phosphoglycerate mutase 1 regulates dNTP pool and promotes homologous recombination repair in cancer cells. J Cell Biol. 2017;216(2):409-424. doi:10.1083/ jcb. 201607008

18. Mathews CK. DNA precursor metabolism and genomic stability. FASEB J. 2006;20(9):1300-1314. doi:10.1096/fj.06-5730rev

19. Kunos CA, Radivoyevitch T, Waggoner S, et al. Radiochemotherapy plus 3-aminopyridine-2-carboxaldehyde thiosemicarbazone (3-AP, NSC \#663249) in advanced-stage cervical and vaginal cancers. Gynecol Oncol. 2013;130(1):75-80. doi:10.1016/j.ygyno.2013.04.019

20. Linehan WM, Ricketts CJ. The metabolic basis of kidney cancer. Semin Cancer Biol. 2013;23(1):46-55. doi:10.1016/j.semcancer.2012.06.002

21. Sudarshan S, Karam JA, Brugarolas J, et al. Metabolism of kidney cancer: from the lab to clinical practice. Eur Urol. 2013;63 (2):244-251. doi:10.1016/j.eururo.2012.09.054
22. Sato Y, Yoshizato T, Shiraishi Y, et al. Integrated molecular analysis of clear-cell renal cell carcinoma. Nat Genet. 2013;45(8):860-867. doi:10.1038/ng.2699

23. Nickerson ML, Jaeger E, Shi Y, et al. Improved identification of von Hippel-Lindau gene alterations in clear cell renal tumors. Clin Cancer Res. 2008;14(15):4726-4734. doi:10.1158/1078-0432.CCR07-4921

24. Ward PS, Thompson CB. Metabolic reprogramming: a cancer hallmark even warburg did not anticipate. Cancer Cell. 2012;21 (3):297-308. doi:10.1016/j.ccr.2012.02.014

25. von Roemeling CA, Marlow LA, Wei JJ, et al. Stearoyl-CoA desaturase 1 is a novel molecular therapeutic target for clear cell renal cell carcinoma. Clin Cancer Res. 2013;19(9):2368-2380. doi:10.1158/ 1078-0432.CCR-12-3249

26. Duxbury MS, Whang EE. RRM2 induces NF-kappaB-dependent MMP-9 activation and enhances cellular invasiveness. Biochem Biophys Res Commun. 2007;354(1):190-196. doi:10.1016/j.bbrc.2006.12.177

27. Rasmussen RD, Gajjar MK, Tuckova L, et al. BRCA1-regulated RRM2 expression protects glioblastoma cells from endogenous replication stress and promotes tumorigenicity. Nat Commun. 2016;7:13398. doi:10.1038/ncomms13398

28. Li C, Zheng J, Chen S, et al. RRM2 promotes the progression of human glioblastoma. J Cell Physiol. 2018;233(10):6759-6767. doi:10.1002/jcp.26529

29. Li J, Pang J, Liu Y, et al. Suppression of RRM2 inhibits cell proliferation, causes cell cycle arrest and promotes the apoptosis of human neuroblastoma cells and in human neuroblastoma RRM2 is suppressed following chemotherapy. Oncol Rep. 2018;40 (1):355-360. doi:10.3892/or.2018.6420

30. Dai L, Lin Z, Qiao J, Chen Y, Flemington EK, Qin Z. Ribonucleotide reductase represents a novel therapeutic target in primary effusion lymphoma. Oncogene. 2017;36(35):5068-5074. doi:10.1038/ onc. 2017.122

31. Grolmusz VK, Karaszi K, Micsik T, et al. Cell cycle dependent RRM2 may serve as proliferation marker and pharmaceutical target in adrenocortical cancer. Am J Cancer Res. 2016;6 (9):2041-2053.

32. Fatkhutdinov N, Sproesser K, Krepler C, et al. Targeting RRM2 and Mutant BRAF is a novel combinatorial strategy for melanoma. Mol Cancer Res. 2016;14(9):767-775. doi:10.1158/1541-7786.MCR-16-0099

33. Zheng S, Wang X, Weng YH, et al. siRNA knockdown of RRM2 effectively suppressed pancreatic tumor growth alone or synergistically with doxorubicin. Mol Ther Nucleic Acids. 2018;12:805-816. doi:10.1016/j.omtn.2018.08.003
OncoTargets and Therapy

\section{Publish your work in this journal}

OncoTargets and Therapy is an international, peer-reviewed, open access journal focusing on the pathological basis of all cancers, potential targets for therapy and treatment protocols employed to improve the management of cancer patients. The journal also focuses on the impact of management programs and new therapeutic agents and protocols on patient perspectives such as quality of life, adherence and satisfaction. The manuscript management system is completely online and includes a very quick and fair peer-review system, which is all easy to use. Visit http://www.dovepress.com/ testimonials.php to read real quotes from published authors. 